\title{
Detection of perforin and tumour necrosis factor $\alpha$ mRNA expressing cells in sclerosing lymphocytic lobulitis of the breast
}

\author{
Robert E Hunger, Mirjana Hristic, Christoph Mueller, Andreas Kappeler, \\ Hans Jörg Altermatt
}

\begin{abstract}
The contribution of a cellular immune response to tissue destruction in sclerosing lymphocytic lobulitis of the breast is not well understood. In this study, comparison of one case with two age matched control cases showed an increased frequency of activated perforin mRNA expressing cells at the site of tissue destruction in lobulitis. Along with the detection of tumour necrosis factor $\alpha$ (TNF $\alpha$ ) mRNA expressing cells in the infiltrates, the striking association of perforin expressing activated cytotoxic cells with remaining gland parenchyma and the high level of perforin mRNA suggests activation of cytotoxic cells in situ. These findings are evidence that cell mediated cytotoxicity plays a significant role in the destruction of mammary gland tissue in sclerosing lymphocytic lobulitis. (f Clin Pathol 1997;50:310-313)
\end{abstract}

Keywords: lymphocytic lobulitis of the breast; autoimmunity; TNF $\alpha$; perforin

Patients with insulin dependent diabetes mellitus may have evidence of autoimmune diseases involving organs other than the pancreatic islets. In rare cases distinct fibrous and lymphocytic lesions of the breast have been described. ${ }^{12}$ The observation that preserved gland tissue is surrounded by dense lymphocytic infiltrates raises the possibility that a cellular immune response, in particular cell mediated cytotoxicity, may play an important role in tissue destruction. There are at least two major pathways of cell mediated cytotoxicity. The first requires exocytosis of several proteins including the pore forming protein perforin and one or several members of a serine protease family called granzymes. Since the genes coding for perforin and granzymes are generally expressed only after specific activation, detection of cells containing transcripts of these genes is often used as a means of localising cytotoxic cells activated in situ. ${ }^{3}$ The second major pathway, which is reported to be perforin independent and does not require exocytosis, can be mainly attributed to Fas mediated induction of apoptosis in target cells. In addition, the cytokine tumour necrosis factor $\alpha(\mathrm{TNF} \alpha)$ has been shown to exert in vitro cytotoxic activities against several target cells. ${ }^{5}$ Involvement of TNF $\alpha$ as a mediator of cell mediated cytotoxicity is also suggested by the structural similarities between TNFa receptor p55 and Fas; both share a homology region supposedly involved in mediating an apoptotic signal. ${ }^{6}$

In this report, we describe a case of a patient with insulin dependent diabetes mellitus who developed a sclerosing lymphocytic lobulitis of the breast. This inflammatory infiltration was associated with massive upregulation of the number of cells expressing mRNA for perforin and for $\mathrm{TNF} \alpha$.

\section{Case report}

A 27 year old woman with a 14 year history of diabetes mellitus type 1 presenting for a routine gynaecological examination was found with a firm lesion of $4 \mathrm{~cm}$ in diameter in the left breast. Although no obvious signs for malignancy were observed, the lump was surgically removed.

Two women (27 and 28 years old), both normoglycaemic and without signs of diabetes mellitus, were chosen as controls. Breast surgery had been undertaken because of breast asymmetry and carcinophobia, respectively.

\section{Methods}

TISSUE PREPARATION

Five representative tissue samples of case 1, and two samples of each control were formaldehyde fixed and paraffin embedded according to standard techniques.

\section{IMMUNOHISTOCHEMISTRY}

Sections of paraffin embedded tissue specimens were dewaxed with xylene and stained with the following antibodies as first stage reagents: rabbit antihuman CD3 (affinity purified; Dako, Denmark); L26 (anti-CD20, Dako); PG-M1 (anti-CD68, Dako); C8/144B (antiCD8, Dako); OPD4 (anti-CD45RO, Dako); VC1.1 (anti-CD57, Dako). Before incubation with the primary antibody, tissue sections were either pretreated with trypsin (Difco 1:250, $0.1 \%, 20$ minutes at $37^{\circ} \mathrm{C}$, for CD3, PG-M1, and VC1.1), or boiled for five minutes in 10 $\mathrm{mM}$ citrate buffer $(\mathrm{pH} 6.0)$ in a pressure cooker (for C8/144B), or left untreated (for L26). Visualisation was done using an avidinbiotin complex (ABC) detection kit (Dako), with a biotinylated swine antirabbit or rabbit antimouse Ig secondary antibody, followed by incubation with $\mathrm{ABC} /$ horseradish peroxidase and the chromogen 3,3'-diaminobenzidine 
(Sigma). In negative controls the primary antibody was replaced with normal rabbit immunoglobulins or with irrelevant isotype matched mouse monoclonal antibodies.

PREPARATION OF ${ }^{35} S$ LABELLED RNA PROBES A 600 bp fragment of the human TNFa $\mathrm{cDNA}^{7}$ (generously provided by Dr R Modlin, UCLA, California, USA) and a 1953 bp cDNA fragment of the human perforin gene ${ }^{8}$ (kindly provided by Dr J Tschopp, University of Lausanne, Switzerland), cloned into the expression vectors pGEM-1 and pBluescript $S K$, respectively were used to prepare ${ }^{35} S$ labelled sense and antisense RNA probes, as previously described. ${ }^{9}$

\section{IN SITU HYBRIDISATION}

In situ hybridisation was performed as previously described. ${ }^{9}$ Hybridised slides were exposed for 28 days at $4^{\circ} \mathrm{C}$, developed and subsequently counterstained with nuclear fast red $(0.05 \%$ in $5 \%$ aluminium sulphate) by standard techniques.

EVALUATION OF SLIDES

After in situ hybridisation with the ${ }^{35} \mathrm{~S}$ labelled antisense RNA probe, cells were considered positive for gene expression when they had at least three times as many silver grains as cells hybridised with the corresponding sense RNA probe, which served as a negative control. For each tissue sample $10-35 \mathrm{~mm}^{2}$ of tissue section were screened under a light microscope. Immunohistochemically stained tissue sections were analysed accordingly.

\section{Results}

HISTOLOGICAL AND IMMUNOHISTOCHEMICAL ANALYSIS

Histological examination of tissue specimens of the breast from our case showed a dense perilobular and periductal fibrosis. Glandular parenchyma was widely absent and atrophic lobular and ductal structures were only rarely found. Preserved glandular elements were surrounded by a dense lymphoplasmocytic infiltrate and intraepithelial lymphocytes were frequently found (fig 1A). $\mathrm{CD}^{+}$cells ( $\mathrm{T}$ cells) were found scattered over the whole tissue section. Maximum frequencies were seen in leucocyte aggregates with close contact to parenchyma (fig 1C). Considerable numbers of $\mathrm{CD}^{+}$cells were located within the epithelium. $\mathrm{CD} 20^{+}$cells (B cells) were less abundant than $\mathrm{T}$ cells. They were preferentially found in mononuclear cell aggregates near remaining parenchyma and were completely absent from the epithelial cell layer. $\mathrm{CD}^{+} 8^{+}$cells (monocytes/macrophages) were found scattered over the whole tissue section with slight preference for remaining parenchyma. Some of them were seen within the epithelial cell layer.

In the cellular infiltrates $48 \%$ of the leucocytes were positive for CD3 ( $\mathrm{T}$ cells), $35 \%$ for CD20 (B cells), and 16\% for CD68 (monocytes/macrophages). CD57 positive cells (natural killer (NK) cells) were only rarely found $(<1 \%)$. Granulocytes were almost absent, as assessed in the haematoxylin and eosin stained sections. There were slightly more $\mathrm{CD}^{+}$than $\mathrm{CD}^{+} \mathrm{T}$ cells $(\mathrm{CD} 4$ to $\mathrm{CD} 8$ ratio: 0.9 ). The frequency of $\mathrm{CD} 3$ positive cells was 32.4 cells per $\mathrm{mm}^{2}$ tissue section (SD 7.0), as assessed on five different tissue samples from our case.

The two controls both showed histological signs of fibrocystic breast disease (fig 1B). CD3 positive cells were found at about the same frequency as in the index case $\left(32.5\right.$ cells per $\mathrm{mm}^{2}$ of tissue section; SD 5.4).

\section{IN SITU HYBRIDISATION}

To further characterise the functions of these infiltrating cells, in situ hybridisations for the specific detection of perforin and $\mathrm{TNF} \alpha$ mRNA were performed. Our patient with sclerosing lobulitis showed an approximately 10fold increase in the number of perforin expressing cells (fig 2) over the controls. The same was true for $\mathrm{TNF} \alpha$ expressing cells. TNF $\alpha$ and perforin expressing cells were preferentially found in close contact with remaining breast epithelia (fig $1 \mathrm{E}$ and $\mathrm{F}$ ). Interestingly, TNF $\alpha$ expressing cells were often located within the epithelial cell layer (fig 1E). No specific accumulation of silver grains was detected in tissue sections hybridised with the corresponding sense probes (fig $1 \mathrm{G}$ and $\mathrm{H}$ ), which served as negative controls.

\section{Discussion}

Data on possible mechanisms operative in the pathogenesis of sclerosing fibrocystic breast disease of diabetic patients have up to now been very limited. Increased HLA-DR expression and association with other autoimmune diseases led to the presumption that these lesions could have an autoimmune pathogenesis. ${ }^{2}$ The relative contributions of humoral and cell mediated immune mechanisms are not clear. However, the absence of autoantibodies in many patients with sclerosing fibrocystic breast disease implies that humoral immune mechanisms are less important. ${ }^{2}$ We report here that cells expressing mRNA of the cytotoxic cell associated perforin gene are present at high frequency in tissue sections of a diabetic patient with sclerosing fibrocystic breast disease. So far expression of the perforin gene has been reported only in activated cytotoxic $T$ cells, preferentially of the CD8 phenotype and NK cells. Since NK cells appear to be almost absent, perforin expressing cells are most probably $\mathrm{T}$ cells. Comparing the relative frequency of $\mathrm{CD} 3 \mathrm{~T}$ cells $(32.4$ cells per $\mathrm{mm}^{2}$ ) and perforin mRNA expressing cells ( 3.9 cells per $\mathrm{mm}^{2}$ ) it can be concluded that more than $10 \%$ of the infiltrating $\mathrm{T}$ cells represent recently activated cytotoxic $\mathrm{T}$ cells. This is probably an underestimation of cytotoxic activity, as other perforin independent cytotoxic effector mechanisms, in particular Fas/ FasL interaction, have been described. ${ }^{4}$ However, the contribution of this latter mechanism, which appears to be mainly operative in $\mathrm{CD}^{+}$ cytotoxic $T$ cells, cannot be assessed on the formaldehyde fixed material available for the present study. The high frequency of perforin expressing cells and the consistently high 


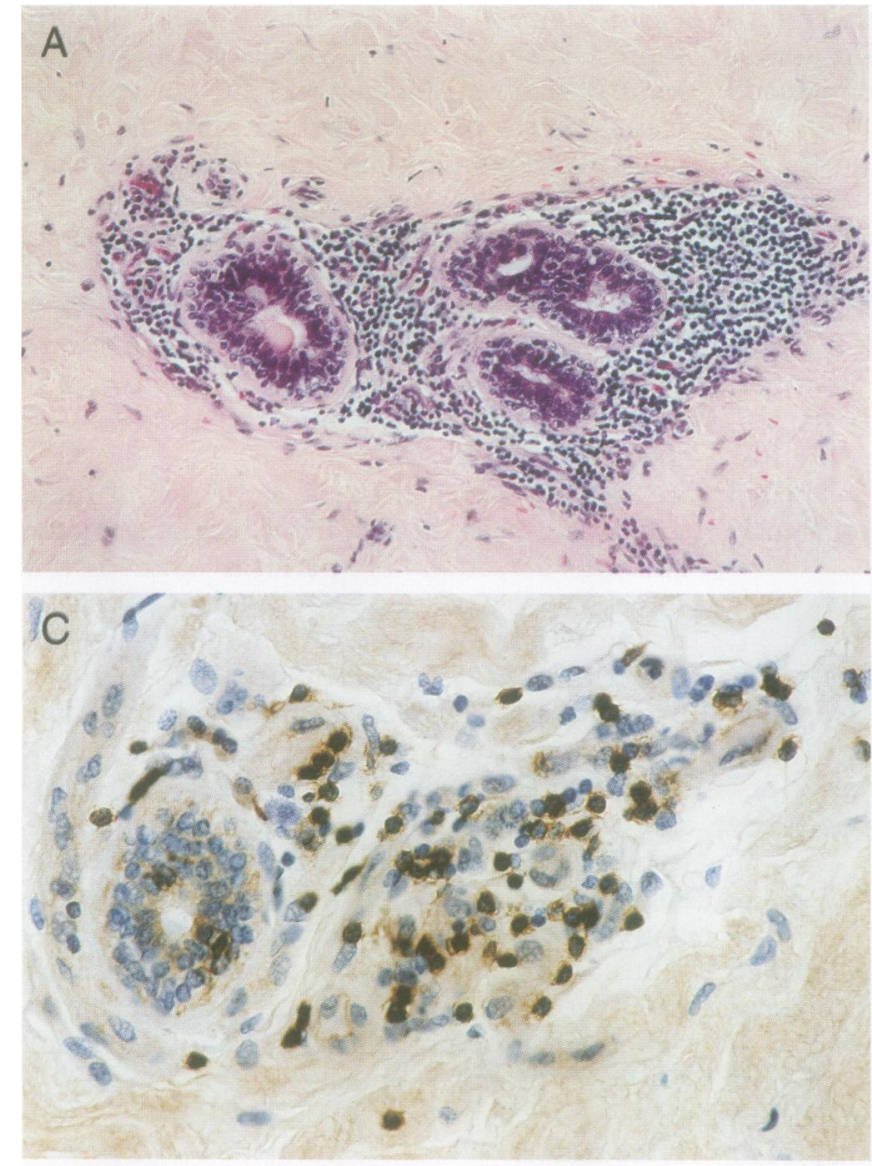

B

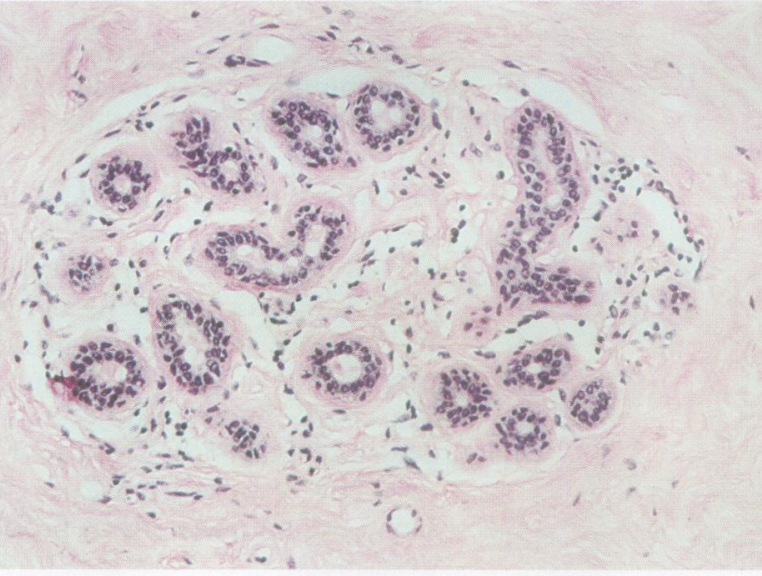

政
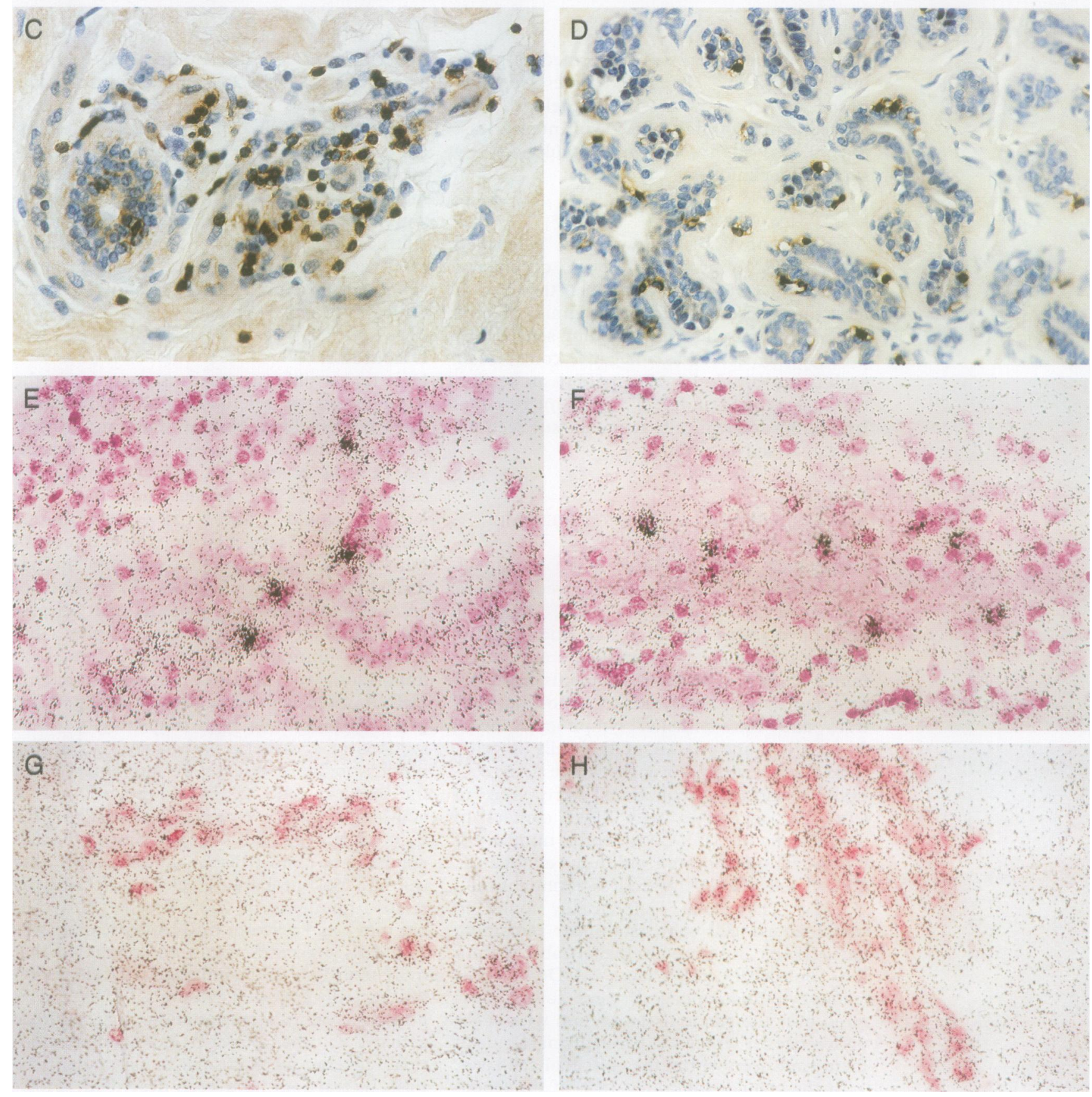

Figure 1 Breast tissue sections of the patient with sclerosing lobulitis and diabetes mellitus $(A, C, E, F)$ and a control patient $(B, D)$. Dense lobular lymphocytic infiltrates are occasionally present in the patient with sclerosing lobulitis $(A)$ whereas lobules of the control reveal only scattered lymphocytes (B). There was no obvious difference in the number of $C D 3^{+}$lymphocytes in the patient with sclerosing lobulitis $(C)$ and the controls $(D)$ (ABC-peroxidase technique, $D A B$, counterstained with haematoxylin). In the patient with sclerosing lobulitis, in situ hybridisation with radioactive labelled riboprobes for the detection of TNF $(E)$ and perforin $(F)$ showed TNFa reactive cells in or in close contact with the remaining epithelium. A similar distribution was found for perforin reactive cells. In situ hybridisations with sense probes of the TNFa $(G)$ and perforin gene $(H)$ as a negative control showed no specific accumulation of silver grains. 


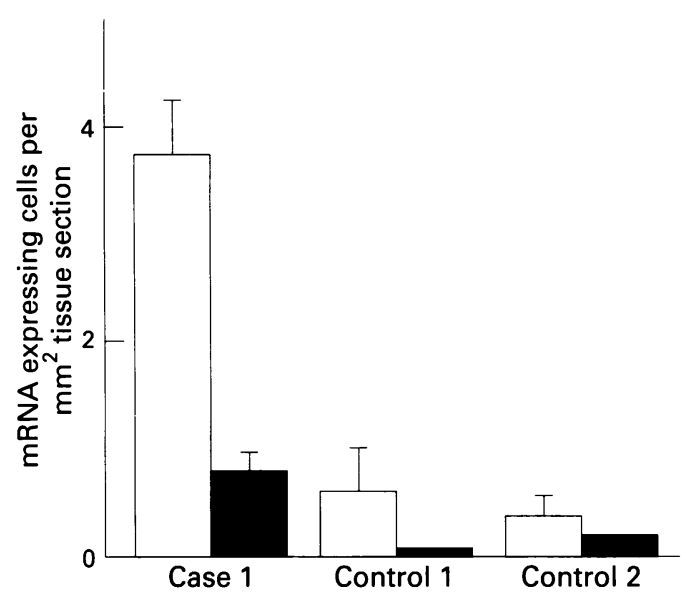

Figure 2 The number of perforin (white bars) and TNFa (black bars) expressing cells per $\mathrm{mm}^{2}$ of tissue cross sections in the patient with sclerosing lobulitis (case 1) shows a severalfold increase when compared to the two controls (controls 1 and 2). Error bars $=S D$.

expression level in these cells, as well as the striking association of these perforin $\mathrm{mRNA}^{+}$ cells with remaining mammary gland structures, indicate an activation of these cytotoxic cells in situ rather than an immigration of previously activated cells at the site of the lesion.

Evidence for the presence of TNF $\alpha$ at the protein or mRNA level has been documented in virtually all inflammatory lesions analysed. ${ }^{5}$ Thus it is not surprising to find this gene being expressed in the cellular infiltrates of sclerosing lymphocytic breast disease. However, several points deserve particular attention. The frequency of TNF $\alpha$ expressing cells is sharply increased when compared to other fibrocystic disorders of the breast (fig 2). TNF $\alpha$ expressing cells were found among intraepithelial leucocytes which include both macrophages/ monocytes and $T$ cells. The precise mode of action of TNF $\alpha$ in the pathogenesis of diabetes associated sclerosing fibrocystic breast disease remains to be determined. One mode of action may be through cytotoxic effects, as has been shown for pancreatic cells in vitro. ${ }^{5}$ Alterna- tively, TNF $\alpha$ has been found to upregulate several cell adhesion molecules on endothelial cell lines ${ }^{10}$; thus this cytokine could exert its function through an increased recruitment of inflammatory cells to the lesions by upregulation of cell adhesion molecules on vascular endothelia. Attempts to detect ICAM-1 by immunohistochemistry gave inconclusive results; we cannot rule out the possibility that fixation of the tissue sample might have lead to structural alterations of the molecule which prevent detection by the monoclonal antibodies used (data not shown).

Taken together, these results support the notion of an autoimmune pathogenesis for sclerosing lymphocytic lobulitis in diabetes mellitus and indicate that cell mediated cytotoxicity represents a major mechanism involved in the massive tissue destruction observed in this disease.

1 Soler NG, Khardori R. Fibrous disease of the breast, thyroiditis, and cheiroarthropathy in type I diabetes mellitus. Lancet 1984; i:193-5.

2 Lammie GA, Bobrow LG, Staunton MD, Levison DA, Page G, Millis RR. Sclerosing lymphocytic lobulitis of the breast--evidence for an autoimmune pathogenesis. Histopathology 1991;19:13-20.

3 Griffiths G, Mueller C. Expression of perforin and granzymes in vivo: potential diagnostic markers for granzymes in vivo: potential diagnostic markers for

4 Henkart PA. Lymphocyte-mediated cytotoxicity: two pathways and multiple effector molecules. Immunity 1994;1: ways and

5 Vassalli $P$. The pathophysiology of tumor necrosis factors. Annu Rev Immunol 1992;10:411-52.

6 Cleveland JL, Ihle JN. Contenders in FasLTNF death signaling. Cell 1995;81:479-82.

7 Pennica D, Nedwin GE, Hayflick JS, Seeburg PH, Derynck $\mathrm{R}$, Palladino MA, et al. Human tumor necrosis factor: precursor structure, expression and homology to lymphotoxin. Nature 1984;312:724-8.

8 Lichtenheld MG, Olsen KJ, Lu P, Lowrey DM, Hameed A, Hengartner $\mathrm{H}$, et al. Structure and function of human perHengartner H, et al. Structure a
forin. Nature 1988;335:448-51.

9 Mueller C, Gershenfeld HK, Lobe CG, Okada CY, Bleackley RC, Weissman IL. A high proportion of T lymphocytes that infiltrate $\mathrm{H}-2$ incompatible heart allografts in vivo express genes encoding cytotoxic cell-specific serine proteases, but do not express the MEL-14-defined lymph node homing receptor. $\mathcal{F} \operatorname{Exp} M e d$ 1988;167:1124-36.

10 Sikorski EE, Hallmann R, Berg EL, Butcher EC. The Peyer's patch high endothelial receptor for lymphocytes, the mucosal vascular addressin, is induced on a murine endothelial cell line by tumor necrosis factor- $\alpha$ and IL-1. $\mathcal{F}$ Immunol 1993;151:5239-50. 